while statistically valid, would not necessarily exclude the existence of an infectious agent in human leukaemia. If, on the other hand, leukaemia is a truly infectious disease, it would be more useful to look for an association between the date and place of residence of one child during the period of infectivity and that of another child during the period of susceptibility to the disease. This suggestion might be extended to a study of the parents of affected children, since they will have had the closest and longest contact with the child. But this illustrates the complexity of the epidemiological problem, since nothing is known of these presumed periods of infectivity and susceptibility, and if the proposition is valid the collection of such information will depend on the development of more refined analytical methods.

The hypothesis that human leukaemia is a contagious disease is appealing, and the evidence from the animal leukaemias provides in itself sufficient reason for the experimental approach in studying the human disease. Isolation of a causative organism offers the hope of rational and effective treatment, both immunological and chemotherapeutic, which in the final analysis can be achieved only in the experimental laboratory. But apart from providing evidence for infective agents the epidemiological approach might point to environmental factors which could be controlled. If leukaemia is an infectious disease it must be one of a very special kind, and perhaps the epidemiologist will discover some of these peculiarities. Moreover, in view of its potentially useful epidemiological value the history of all cases of leukaemia should be as detailed as possible and should include information on exposure to other human infections or prolonged contact with animals, insects, and chemical agents.

\section{Diverticular Disease of the Colon}

Maxwell Telling and O. C. Gruner, ${ }^{1}$ of Leeds, gave an exhaustive account in 1917 of the natural history of diverticulosis of the colon. But not until recently was much attention paid to the aetiology of this common and increasingly important condition.

The diverticula may occur anywhere in the colon but congregate especially in the sigmoid. They lie in two columns alongside the lateral taeniae coli, where they are often overlapped by the appendices epiploicae. Unlike diverticula of the small bowel, which project into the mesentery, the colonic diverticula never protrude primarily into the mesocolon. The distribution of colonic diverticula corresponds precisely to the points of penetration of the blood vessels into the bowel wall, as $\mathrm{H}$. Drummond ${ }^{2}$ first showed, and they doubtless produce areas of weakness in the colonic musculature.

Basil Morson ${ }^{3}$ made an important contribution to our knowledge of the aetiology of this disease by taking attention away from the saccules themselves and concentrating more on the colonic wall. He reported his investigations of 173 specimens of colon removed for diverticulitis at St. Mark's Hospital, London. Of these, 112 (64\%) showed evidence of diverticulitis, which was extersive in 67 and focal in 45 cases. In 61 specimens there was no inflammation at all, and 5 of these indeed did not even show diverticula, yet in all cases operation had been performed because diverticulitis had been diagnosed on both clinical and radiological evidence. However, all the specimens showed striking abnormalities in the muscle wall. The taeniae coli were thickened and almost cartilaginous ; the circular muscle was also thickened and arranged in concertina-like folds, with the orifices of the diverticula opening between their corrugations. This thickening of the plain muscle appeared to be a shortening rather than a true hypertrophy, and it accounted for the characteristic redundancy of the mucosa, which was itself thrown into folds and appeared to contribute to the obstruction so common in this condition.

N. S. Painter and S. C. Truelove ${ }^{4}$ have shown by cineradiography and other methods that the resting pattern of pressures in the normal sigmoid colon and in the colon affected by diverticulosis is the same, but very high pressures develop in the diseased segments in response to morphine and prostigmine. In these cases cineradiography showed that the colon was divided by contraction rings into a series of segments whose outflow was obstructed, and the consequent localized high pressures were seen on occasions to distend the related diverticula considerably. There is thus in diverticular disease good evidence of abnormal segmentation and the gereration of high pressures after certain drugs, together with histological proof of an abnormal circular muscle. Investigation of other causes of excessive segmentation-diet, drugs, and purgatives, for example-may lead to important information on the pathogenesis of diverticulosis. Dietary factors may well be of importance. Diverticulosis is a common condition in so-called civilized communities which enjoy a refined diet and is extremely rare in less sophisticated populations living on a bulky vegetable diet. ${ }^{6}$

Not only are we still ignorant about the exact aetiology of diverticulosis, but also there is a surprising lack of accurate information on its frequency in the population as a whole. The incidence has been calculated from barium-enema studies on hospital patients and from post-mortem examinations, both highly selected population groups. However, the investigations have certainly given some useful information. Thus T. P. Dearlove, ${ }^{7}$ in his extensive necropsy study of nearly 7,000 cases at the Royal Adelaide Hospital, found that diverticulosis was almost unknown under the age of 40 years. In the $40 \mathrm{~s}$ the incidence rose to approximately $1 \%$, in the 50 s to $1.7 \%$, in the 60 s to $3.5 \%$, and in patients over the age of 70 years to $7 \%$. Large series of patients examined by barium enema have shown diverticula in 5 to $10 \%$ of the cases.

In this issue of the B.M.f. Dr. Truelove together with Drs. O. N. Manousos and K. Lumsden present an important study of a barium follow-through examination on 109 persons without gastrointestinal symptoms (page 762). Twenty were found to have diverticula. Above the age of 6015 out of 43 people had them (about one in three), and below that age 5 out of 66 . None of the 14 people under the age of 40 had any diverticula. The condition was more common in women than in men. Though the numbers are comparatively small, the study is of particular value in that it deals with a population either healthy or at least completely free of gastrointestinal symptoms. It therefore gives a good indication of the incidence of colonic diverticula in the general population in Britain.

As to the aetiology of colonic diverticula, it is interesting that these workers, in a separate study reported at page 760 , have found the colonic transport time to be considerably shorter in patients with diverticula than in normal persons,

\footnotetext{
Telling, W. H. M., and Gruner, O. C., Brit. F. Surg., 1917, 4, 468. 2 Drummond, H., ibid., 1917, 4, 407.

Morson, B. C., Proc. roy. Soc. Med., 1963, 56, 798.

Painter, N. S., and Truelove, S. C., Brit. med. F., 1963, 2, 33. - Ann. roy. Coll. Surg. Engl., 1964, 34, 98.

- Campbell, G. D., Brit. med. F., 1967, 3, 243.

Thearlove, T. P., Med. f. Aust., 1954, 1, 470.
} 
and the same fast transit time was noted in patients with the irritable colon syndrome. They conclude that their evidence supports the hypothesis that incoordinated colonic activity is the basic abnormality in diverticular disease of the large bowel.

\section{New Respiratory Virus}

The complex aetiology of acute respiratory disease has been gradually revealed during the past fifteen years with the discovery of one after another "new" virus. Each one in turn has been studied for its pathogenesis in man and eventually allotted a place in one of the various virus families on the basis of its physical, chemical, and morphological properties.

The myxovirus family, besides having the true influenza viruses $A, B$, and $C$, has had added to it five different parainfluenza viruses and probably also the respiratory syncytial virus. The adenovirus family contains 31 different serotypes, and the picornavirus family, the home of poliomyelitis, E.C.H.O., and Coxsackie viruses, now shelters about 80 rhinoviruses, all isolated from patients with common colds.

The veils of mystery surrounding respiratory illness are gradually being lifted. With the right technique one of these many organisms can increasingly be found to be the cause of disease. However, there still remains a fair proportion of cases in which nothing can be found to account for the patient's symptoms and the hunt is by no means over.

A new technique developed by B. Hoorn and D. A. J. Tyrrell $^{1}$ involved the use of fragments of trachea and nasal epithelium from the human embryo to provide an "organ culture" for the viruses. This procedure was found to increase the frequency of virus isolation from patients with colds to a considerable extent. The viruses grown in this way were sometimes familiar ones which could be grown in tissue culture, but it was quickly recognized that there were others which were clearly multiplying in the organ cultures and producing colds in volunteers, but refusing to behave like other viruses in ordinary tissue cultures.

D. Hamre and J. J. Procknow ${ }^{2}$ had earlier isolated from students with colds some other fastidious viruses, which, though they grew in tissue culture, did so only with special techniques. J. D. Almeida and Tyrrell ${ }^{3}$ then put these fastidious viruses and those grown on organ culture under the electronmicroscope and discovered not only that the two groups were morphologically similar but that they differed from the usual human respiratory viruses. Though the new viruses contain R.N.A. and are destroyed by ether, and have therefore some characters of the myxoviruses, in their structure they can be readily distinguished. In place of the fine frill surrounding the myxovirus particle well-spaced wedgeshaped projections can be seen in these viruses round the circumference of the particle. It was also noted that these human viruses were apparently identical in structure with a virus known to cause infectious bronchitis in fowls and with one causing hepatitis in mice.

So far as is known neither of these last two viruses is pathogenic for man, but antibody to mouse hepatitis virus

'Hoorn, B., and Tyrrell, D. A. J., Brit. F. exp. Path., 1965, 46, 109. Hamre, D., and Procknow, J. J., Proc. Soc. exp. Biol. (N.Y.), 1966, 121, 190 .

s Almeida, J. D., and Tyrrell, D. A. J., f. gen. Virol., 1967, 1, 175.

- Hartley, J. W., Rowe, W. P., Bloom, H. H., and Turner, H. C., Proc. Soc. exp. Biol. (N.Y.), 1964, 115, 414.

- McIntosh, K., Dees, J. H., Becker, W. B., Kapikian, A. Z., and Chanock, R. M., Proc. nat. Acad. Sci. (Wash.) 1967, 57, 933. has been detected in human sera, and J. W. Hartley and colleagues, ${ }^{4}$ investigating respiratory illness among military recruits, detected during three successive winters a wave of serological changes suggesting that the recruits had experienced an epidrmic of infection with mouse hepatitis virus or with a virus if a similar antigenic composition.

A further six strains of this virus with the new look were isolated by K. McIntosh and colleagues, ${ }^{5}$ who extended their studies of respiratory disease to include organ culture. Since they had not included symptomless controls in their series, they were unable to be certain that the viruses were in fact responsible for the disease. The evidence was certainly suggestive, as was that obtained by Hamre and Procknow, ${ }^{2}$ whose isolates were in every case but one from patients with illness. But it was clear that a strain would have to be tested in human volunteers under controlled conditions if this point was to be decided for certain.

In this issue of the B.M.F. Mr. A. F. Bradburne, Dr. M. L. Bynoe, and Dr. Tyrrell produce evidence that this virus has a pathogenic role (page 767). Twenty volunteers given saline remained healthy, whereas half of those given virus developed a fairly typical common cold with a profuse nasal discharge, mild fever, and a significant rise in serum antibody to the virus.

The connexion of what must now be recognized as a human respiratory pathogen with the morphologically identical fowl and mouse viruses has still to be determined. Preliminary results suggest they are serologically distinct, and it appears that we have a whole new virus family with possibly multiple serotypes. Another veil is down ; our ignorance is less ; but every additional virus must dampen our hopes for a vaccine to control acute respiratory illness.

\section{Overwhelming Infection after Splenectomy}

A late complication of splenectomy is fulminating generalized infection. This hazard was first reported in 1952 by $\mathrm{H}$. King and H. B. Shumacker in five infants who had undergone splenectomy for hereditary spherocytosis. ${ }^{1}$ Though the relationship between splenectomy and overwhelming infection has been doubted, ${ }^{2}{ }^{3}$ most people agree that there is a significant connexion between the two. Children are more vulnerable than adults, and most cases of infection occur within the first few years of splenectomy. ${ }^{45}$

A. J. Eraklis and his colleagues ${ }^{6}$ have recently reviewed 467 cases of splenectomy followed up for at least three years, and in many instances up to ten years. They found that about $5 \%$ of patients died of overwhelming infection, and that the incidence of this disaster depended on the antecedent condition. No patient whose spleen was removed because of traumatic rupture, idiopathic thrombocytopenic purpura, extrahepatic portal-vein thrombosis and portal hypertension, or localized tumour died of infection. The incidence was very low in those with hereditary spherocytosis and aplastic anaemia, but it was higher in cases of thalassaemia major,

King, H., and Shumacker, H. B., Ann. Surg., 1952, 136, 239.

2 Gofstein, R and Gellis, S. S., Amer f. Dis. Child., 1956, 91, 566

s Laski, B., and MacMillan, A., Pediatrics, 1959, 24, 523.

- Laski, B., and MacMillan, A., Pediatrics, 1959, 24, S23. Med., 1957, 22, 390 .

Horan, M., and Colebatch, J. H., Arch. Dis. Childh., 1962, 37, 398.

Eraklis, A. J., Kevy, S. V., Diamond, L. K., and Gross, R. E., New Engl. f. Med., 1967, 276, 1225.

Aldrich, R. A., Steinberg, A. G., and Campbell, D. C., Pediatrics, $1954,13,133$. 